\title{
The use of complementary and alternative medicines among patients with locally advanced breast cancer - a descriptive study Lucy K Helyer ${ }^{1}$, Stephen Chin², Betty K Chui ${ }^{2}$, Barbara Fitzgerald ${ }^{2}$, Sunil Verma ${ }^{2}$, Eileen Rakovitch ${ }^{3}$, George Dranitsaris ${ }^{3,4}$ and Mark Clemons*2
}

\begin{abstract}
Address: ${ }^{1}$ Department of Surgical Oncology, Toronto-Sunnybrook Regional Cancer Centre, Sunnybrook and Women's College Health Sciences Centre, 2075 Bayview Ave, Toronto, ON, M4N 3M5, Canada, 2Division of Medical Oncology, Toronto-Sunnybrook Regional Cancer Centre, Sunnybrook and Women's College Health Sciences Centre, 2075 Bayview Ave, Toronto, ON, M4N 3M5, Canada, ${ }^{3}$ Department of Radiation Oncology, University of Toronto, Cancer Care, Ontario, canada and ${ }^{4}$ Department of Radiation Oncology, University of Toronto, Cancer Care Ontario, 600 University Ave Toronto, ON Canada

Email: Lucy K Helyer - Lhelyer@dal.ca; Stephen Chin - 2sc14@qlink.queensu.ca; Betty K Chui - betty.chui@utoronto.ca; Barbara Fitzgerald - Barbara.Fitzgerald@sw.ca; Sunil Verma - Sunil.Verma@sw.ca; Eileen Rakovitch - Eileen.Rakovitch@sw.ca; George Dranitsaris - dranitsa@uhn.res.utoronto.ca; Mark Clemons*-Mark.Clemens@sw.ca

* Corresponding author
\end{abstract}

Published: 2I February 2006

BMC Cancer 2006, 6:39 doi:10.1186/147|-2407-6-39
Received: 19 May 2005

Accepted: 21 February 2006

This article is available from: http://www.biomedcentral.com/l47I-2407/6/39

(C) 2006 Helyer et al; licensee BioMed Central Ltd.

This is an Open Access article distributed under the terms of the Creative Commons Attribution License (http://creativecommons.org/licenses/by/2.0), which permits unrestricted use, distribution, and reproduction in any medium, provided the original work is properly cited.

\begin{abstract}
Background: Complementary and alternative medicine (CAM) use is common among cancer patients. This paper reviews the use of CAM in a series of patients with locally advanced breast cancer (LABC).

Methods: Women with LABC attending a specialist clinic at a single Canadian cancer centre were identified and approached. Participants completed a self-administered survey regarding CAM usage, beliefs associated with CAM usage, views of their risks of developing recurrent cancer and of dying of breast cancer. Responses were scored and compared between CAM users and non-users.

Results: Thirty-six patients were approached, 32 completed the questionnaire (response rate $89 \%$ ). Forty-seven percent of LABC patients were identified as CAM users. CAM users were more likely to be younger, married, in a higher socioeconomic class and of Asian ethnicity than non-users. CAM users were likely to use multiple modalities simultaneously (median 4) with vitamins being the most popular (60\%). Motivation for CAM therapy was described as, "assisting their body to heal" (75\%), to 'boost the immune system' (56\%) and to "give a feeling of control with respect to their treatment" (56\%). CAM therapy was used concurrently with conventional treatment in $88 \%$ of cases, however, $12 \%$ of patients felt that CAM could replace their conventional therapy. Psychological evaluation suggests CAM users perceived their risk of dying of breast cancer was similar to that of the non-Cam group (33\% vs. $35 \%$ ), however the CAM group had less severe anxiety and depression.

Conclusion: The motivation, objectives and benefits of CAM therapy in a selected population of women with $L A B C$ are similar to those reported for women diagnosed with early stage breast cancer. CAM users display less anxiety and depression and are less likely to believe they will die of their breast cancer. However the actual benefit to overall and disease free survival has yet to be demonstrated, as well as the possible interactions with conventional therapy. Consequently more research is needed in this evergrowing field.
\end{abstract}




\section{Background}

Cancer patients take a wide range of complementary and alternative medicines (CAM). These include ingested therapies such as herbs, and vitamins, homeopathic remedies and traditional Chinese medicines as well as psychological, physical and spiritual techniques [1-4]. Currently between $20 \%$ and $84 \%$ of cancer patients are using CAM therapies [1-6]. Predisposing characteristics for CAM use have been shown to include a high level of education, high-income bracket, ethnicity, marital status, adjuvant therapy and presence of anxiety or depression [1-3,7-9].

While no data reports improved survival or disease free interval with the use of CAM [10], many cancer patients attribute CAM therapy with providing them a feeling of control over their disease. CAM therapies are also believed to have properties such as, 'boosting' the immune system and preventing/treating cancer $[2,11]$. Studies comparing CAM use in women with advanced stage cancer to those with early stage cancer find goals of therapy to be similar, therapeutic and psychological [11]: i.e. to relieve symptoms $[2,5,9,11]$, to exude greater control over their life and express hopefulness over there disease and life [7].

Patients with locally advanced breast cancer (LABC) are a unique population. They have tumours that are frequently large, involve the regional lymph nodes or extend beyond the breast tissue [12]. Even with aggressive therapy the 5year survival rate for these patients is poor at around 55\% [13].

We recently reported in a population of women with breast cancer including all stages of disease, that CAM users are more likely to be younger, better educated and in full time employment compared to non-users [14]. In addition while there was no difference between CAM usage with respect to tumour stage, CAM therapy was associated with an increased perception of breast cancer recurrence and of breast cancer-related death [14].

The objective of this study was to identify the overall usage of CAM in patients with $\mathrm{LABC}$, determine their motivation and objectives for usage. Secondarily the effect of CAM therapy on patient's beliefs and perceptions of their disease was examined.

\section{Methods}

The breast cancer site at the Toronto-Sunnybrook Regional Cancer Centre (TSRCC) has Canada's only specialist multidisciplinary clinic for women with LABC. Between June 2003 and June 2004 consecutive outpatients with a diagnosis of breast cancer were screened for eligibility. Only patients with locally advanced breast cancer were included in this study. Patients were invited to participate in this study examining the prevalence of CAM therapy by a study nurse prior to their visit with their oncologist. All surveys were completed under the supervision of a trained data manager in a private room, and any questions or concerns were addressed by their own oncologist (ER or MC). Patients were reassured that participation in this study in no way altered there medical care. Patients were excluded if they did not have English proficiency or did not give informed consent. Independent confirmation of diagnosis, stage and treatment in all patients was performed by one of the investigators (ER or $\mathrm{MC})$. Study approval was obtained from the local Research and Ethics Board.

The self-administered questionnaire (additional file: 1) was developed to obtain information on demographics, conventional therapy and CAM use [14]. Sixteen of the most common reasons for using CAM and patient perceptions of CAM therapy were derived from the current literature and listed as choices [2]. Patient's beliefs and perceptions of their disease were assed using a Likert scale with larger scores representing higher perceptions of risk [14]. Beliefs were scored on a scale ranging from 1 (strongly disagree) to 5 (strongly agree), while perceptions were scored on a scale from very unlikely $(-2)$ to highly likely $(+2)$.

The Hospital Anxiety and Depression scale was used to assess psychological distress [15]. This instrument gives separate measures of anxiety and depression with seven items for anxiety and seven items for depression (range of scores from 0 to 21). Each item (anxiety and depression) is scored separately. Scores $<7$ represent a non-case, scores 8-10 represent a possible case and those above 10 represent significant disease related to anxiety or depression. The sensitivity of this test has been reported to be $74 \%$ with a specificity of $75 \%$ [16].

Due to the small number of patients the results of this study are presented descriptively as means, medians and proportions. Statistical examination was unable to show significant difference between the CAM users and Non CAM users due to small sample size and inadequate statistical power. Use of comparative tests would have increased the probability of a type I error.

\section{Results}

\section{Demographics}

Thirty-two of the 36 patients approached completed the questionnaire (response rate of $89 \%$ ). Patient demographics are outlined in Table 1. All patients were female, mean age of 54 (range 29-91 years). Fifteen of the 32 patients $(47 \%)$ were identified as CAM users. The CAM users tended to be younger (mean 49 years vs. 59 years) and $86 \%$ were in a current relationship versus $52 \%$ of non-Cam users. Over $80 \%$ of both groups had completed 
Table I: Demographics of the LABC population

\begin{tabular}{lrrr}
\hline & All LABC Patients $n=32$ & CAM Patients $n=15$ & Non-CAM Patients $n=17$ \\
\hline $\begin{array}{l}\text { Mean Age (years) } \\
\text { Range }\end{array}$ & 29 to 91 & 49 & 59 \\
\hline
\end{tabular}

\section{Ethnic Background}

\begin{tabular}{lrrr}
\hline African-Canadian & $9 \%$ & $0 \%$ & \\
Asian & $9 \%$ & $13 \%$ & $5 \%$ \\
Caucasian & $46 \%$ & $40 \%$ & \\
Jewish & $9 \%$ & $20 \%$ & $0 \%$ \\
Middle Eastern & $3 \%$ & $0 \%$ & $0 \%$ \\
Mixed Ethnicity & $3 \%$ & $0 \%$ & \\
Unknown & $6 \%$ & $13 \%$ & $0 \%$ \\
\hline
\end{tabular}

\section{Marital Status}

\begin{tabular}{lrrr}
\hline Married/Common Law & $68 \%$ & $86 \%$ & $52 \%$ \\
Widowed/Divorced & $12 \%$ & $0 \%$ & $23 \%$ \\
Single & $18 \%$ & $13 \%$ & $23 \%$ \\
\hline
\end{tabular}

\section{Education:}

\begin{tabular}{llll}
\hline Did not completed & $12 \%$ & $13 \%$ & $11 \%$ \\
Completed high school & $34 \%$ & $33 \%$ & $35 \%$ \\
Completed university/college & $31 \%$ & $40 \%$ & $23 \%$ \\
Completed Post Graduate Degree & $21 \%$ & $13 \%$ & $29 \%$
\end{tabular}

\section{Employment Status}

\begin{tabular}{lrrr}
\hline Full time & $28 \%$ & $26 \%$ & \\
Part time & $6 \%$ & $13 \%$ & $0 \%$ \\
Unemployed/homemaker & $31 \%$ & $20 \%$ & $41 \%$ \\
Sick Leave & $34 \%$ & $40 \%$ & $29 \%$
\end{tabular}

\section{Household Income (10,000 CND)}

\begin{tabular}{lrrr}
\hline $0-30$ & $25 \%$ & $33 \%$ & \\
$31-70$ & $41 \%$ & $33 \%$ & \\
$71-100$ & $9 \%$ & $18 \%$ & $50 \%$ \\
$>100$ & $22 \%$ & $20 \%$ & $25 \%$
\end{tabular}

\section{Breast Cancer Therapies}

\begin{tabular}{llll}
\hline Surgery & $40 \%$ & $46 \%$ & $35 \%$ \\
Chemotherapy & $81 \%$ & $93 \%$ & $70 \%$ \\
Radiation Therapy & $25 \%$ & $33 \%$ & $17 \%$ \\
Hormonal Therapy & $37 \%$ & $40 \%$ & $35 \%$ \\
\hline
\end{tabular}

high school, while 30\% in the non-CAM users had a graduate degree compared with $13 \%$ in the CAM group. The numbers of patients remaining at work, on sick leave, or at home were comparable as was income distribution between groups. The diverse ethnic population reflects our patient population.

\section{Conventional therapy}

The CAM user group was more likely to have had more intensive therapy for breast cancer, $30 \%$ of patients in the CAM group had all three modalities of treatment; surgery, chemotherapy and radiation in comparison with $14 \%$ in the non CAM user group (Table 1). The use of hormonal therapy was equal between the groups. The presence of 
private insurance and a family physician was also more common in those using CAM techniques (66\% vs. $58 \%$ ) and $(100 \%$ vs. $88 \%)$ respectively. CAM users were also more likely to be involved in cancer support groups $(20 \%$ vs. $5 \%$ ) and if not, more interested in joining one than their counter parts $(25 \%$ vs. $13 \%)$.

\section{Complementary medicine}

The use of complementary alternative medicine was divided into dietary, herbal-homeopathy, psychological and physical methods (Table 2). Many patients used more than one modality with a mean of 4 , (range 1-11). Forty percent of the CAM group had used these techniques prior to their diagnosis of breast cancer and all continued throughout therapy. The most common source of information about complementary medicine was a conventional physician $(40 \%)$ followed by pharmacist and friend (20\%). Two thirds of patients (10) researched CAM therapy prior to starting, 5 patients paid for consultation with prices ranging from $\$ 60$ to $\$ 200 \mathrm{CDN}$. The cost of CAM varied between patients with the majority spending up to $\$ 50 \mathrm{CDN} / \mathrm{month}(46 \%)$ some however spending over $\$ 100 \mathrm{CDN} /$ month $(23 \%)$.

The most common form of CAM was vitamin therapy, and over $60 \%$ of CAM users had taken supplements and additives. Forty percent of the patients using CAM were on restrictive diets; either low in fat, vegetarian or using soy products. Two thirds of patients used psychological techniques including faith and spiritual healing $(40 \%)$ and guided imagery (26\%). 86\% of patients felt their CAM was helpful and beneficial for their disease. Sixty four percent of patients using CAM had informed their oncologist and believed it was important information for their oncologist to know.

\section{Beliefs associated with CAM}

Patients' reasons and beliefs regarding CAM therapy were explored asking questions phrased, "Do you believed CAM......?"(Table 3). The most common reason for CAM use in this population was "to assist the body's natural forces to heal" $(75 \%)$. Other common reasons were: to assist other treatments (62\%), relieve symptoms (62\%), and increase quality of life (62\%). 56\% felt there would not be any side effects and $43 \%$ believed that CAM was perfectly safe with no adverse effects or interactions with other cancer therapies. $12.5 \%$ of patients felt that CAM therapy would make them less likely to accept conventional treatments and $18 \%$ believed it would reduce the chance that other therapies would work. Two patients refused conventional treatment, believing the CAM therapy would cure their breast cancer. One quarter of patients believed CAM therapy would prevent the spread of their disease and $18 \%$ believed it would cure the cancer. Half of respondents were indifferent with respect to the belief that
Table 2: CAM use among LABC patients $(n=15)$

\begin{tabular}{|c|c|}
\hline Mode of CAM Use: & $\%$ Population $(n=15)$ \\
\hline \multicolumn{2}{|l|}{ Dietary } \\
\hline Macrobiotic & 13 \\
\hline Vitamin therapy & 66 \\
\hline Megavitamins & 20 \\
\hline Minerals & 40 \\
\hline Low-fat or vegetarian diets & 40 \\
\hline Soy Products & 26 \\
\hline Herbal/Homeopathy & 20 \\
\hline \multicolumn{2}{|l|}{ Psychological Methods } \\
\hline Meditation & 10 \\
\hline Guided Imagery & 26 \\
\hline Hypnosis & 6 \\
\hline Faith and Spiritual & 40 \\
\hline \multicolumn{2}{|l|}{ Physical Methods } \\
\hline Massage therapy & 26 \\
\hline Acupuncture & 6 \\
\hline Acupressure & 6 \\
\hline Yoga & 26 \\
\hline Tai Chi & 13 \\
\hline \multicolumn{2}{|l|}{ Alternative Providers: } \\
\hline Chiropractor & 6 \\
\hline Naturopathic Doctor & 6 \\
\hline Acupuncturist & 6 \\
\hline TCM Doctor & 6 \\
\hline Others & 13 \\
\hline
\end{tabular}

CAM therapy would cure their cancer, prevent its spread and/or prevent a recurrence.

\section{Perceived risk of breast cancer and associated anxiety and depression}

The risk assessment asked four questions to show patients' perception of developing and dying of recurrent breast cancer. CAM users believed they would more likely die of something other than their breast cancer ( $72 \%$ vs $42 \%$ ) and their cancer was less likely to recur elsewhere after treatment (53\% vs $35 \%)$. However over $60 \%$ of all patients with LABC (CAM users and non-users) felt there disease would not recur in the treated breast or cause their death (Table 4).

The Hospital Anxiety and Depression Scale (HADS) [15] (figure 1) was included to demonstrate the psychological health of the patient population. Anxiety was seen in both groups CAM user and non-CAM user. Those patients using CAM therapy has less severe anxiety. The highest anxiety scores in the CAM group were recorded in patients using greater than four modalities of CAM. CAM users' 
Table 3: Beliefs and perceptions of CAM therapy $(n=15)$.

\begin{tabular}{|c|c|c|c|}
\hline \multirow{2}{*}{$\begin{array}{l}\text { Beliefs } \\
\text { I believe CAM therapy will }\end{array}$} & \multicolumn{3}{|l|}{ Percentages } \\
\hline & Unlikely $(I, 2)$ & Indifferent (3) & Likely $(4,5)$ \\
\hline Cure Cancer & $31.3 \%$ & $50.0 \%$ & $18.8 \%$ \\
\hline Prevent Spread & $25.0 \%$ & $\mathbf{5 0 . 0} \%$ & $25.0 \%$ \\
\hline Assist other treatments & $25.0 \%$ & $12.5 \%$ & $62.5 \%$ \\
\hline Relieve symptoms & $18.8 \%$ & $18.8 \%$ & $62.5 \%$ \\
\hline Have side effects & $56.3 \%$ & $12.5 \%$ & $31.3 \%$ \\
\hline Weaken body's natural reserves & $62.5 \%$ & $18.8 \%$ & $18.8 \%$ \\
\hline Patient's Fault if they don't work & $75.0 \%$ & $18.8 \%$ & $6.3 \%$ \\
\hline Assist the body's natural forces to heal & $6.3 \%$ & $18.8 \%$ & $75.0 \%$ \\
\hline Easy to understand how they work & $37.5 \%$ & $25.0 \%$ & $37.5 \%$ \\
\hline Boost to Immune System & $18.8 \%$ & $25.0 \%$ & $56.3 \%$ \\
\hline Perfectly safe & $25.0 \%$ & $31.3 \%$ & $43.8 \%$ \\
\hline Increase Quality of Life & $6.3 \%$ & $31.3 \%$ & $62.5 \%$ \\
\hline Feeling of control over the cancer & $25.0 \%$ & $18.8 \%$ & $56.3 \%$ \\
\hline Prevent recurrence of Cancer & $18.8 \%$ & $56.3 \%$ & $25.0 \%$ \\
\hline Reduce the chance that other therapies will work & $37.5 \%$ & $43.8 \%$ & $18.8 \%$ \\
\hline Makes them less likely to accept conventional treatments & $50.0 \%$ & $37.5 \%$ & $12.5 \%$ \\
\hline
\end{tabular}

described their depression as mild more frequently in comparison to the non-CAM users.

\section{Discussion}

Depending on the population studied, the prevalence of CAM use among breast cancer patients is $20 \%-84 \%$ [1-6]. Forty seven percent of patients with LABC at our institution were CAM users, similar to the proportion of users in a non-stage specific group at our institution [14]. Variance in degree of use has been attributed to socio-demographic and clinical differences in study populations more so than stage of disease.

Women with LABC are a unique population. They present to medical attention with breast cancer at an advanced stage and they therefore have a poorer prognosis [17]. Reasons proposed for presentation with advanced disease depends largely on the population studied and may include the biology of the tumour, unwillingness of the patient to consult medical attention due to fear, denial [18] or pursuit of alternative therapy [19-21], or lack of patient education [22] but is largely unknown. Most patients, as in our study, use CAM therapy as an adjunct to conventional treatment $[2,5]$. Only $12 \%$ of our patients refused conventional treatment preferring CAM alternatives. Despite widespread use of CAM therapy among cancer patients, the efficacy in the course of cancer therapy has not been substantially confirmed $[10,18]$. Jacobson $e t$ al. reviewed English language publications from 1980 to 1997, looking for supportive evidence for CAM therapy and although most studies lacked vigorous scientific design, there was no definite survival benefit with the addition of CAM therapy [10]. Physical methods such as acupuncture, massage and mind-body techniques have

Table 4: Risk perception in LABC patients

\begin{tabular}{|c|c|c|}
\hline $\begin{array}{l}\text { Risk Perception } \\
\text { How likely is it that....? }\end{array}$ & Non CAM Users \% people who rated $(n=17)$ & CAM Users \% people who rated $(n=15)$ \\
\hline \multicolumn{3}{|c|}{ Cancer recurrence in same breast } \\
\hline Unlikely & $53(9)$ & $57(8)$ \\
\hline Likely & $47(8)$ & $43(7)$ \\
\hline \multicolumn{3}{|c|}{ Cancer recurrence elsewhere } \\
\hline Unlikely & $35(6)$ & $53(8)$ \\
\hline Likely & $65(11)$ & $47(7)$ \\
\hline \multicolumn{3}{|l|}{ Likely die of cancer } \\
\hline Unlikely & $65(11)$ & $67(10)$ \\
\hline Likely & $35(6)$ & 33.(5) \\
\hline \multicolumn{3}{|c|}{ Likely die of something else } \\
\hline Unlikely & $58(10)$ & $27(4)$ \\
\hline Likely & $42(7)$ & $73(11)$ \\
\hline
\end{tabular}



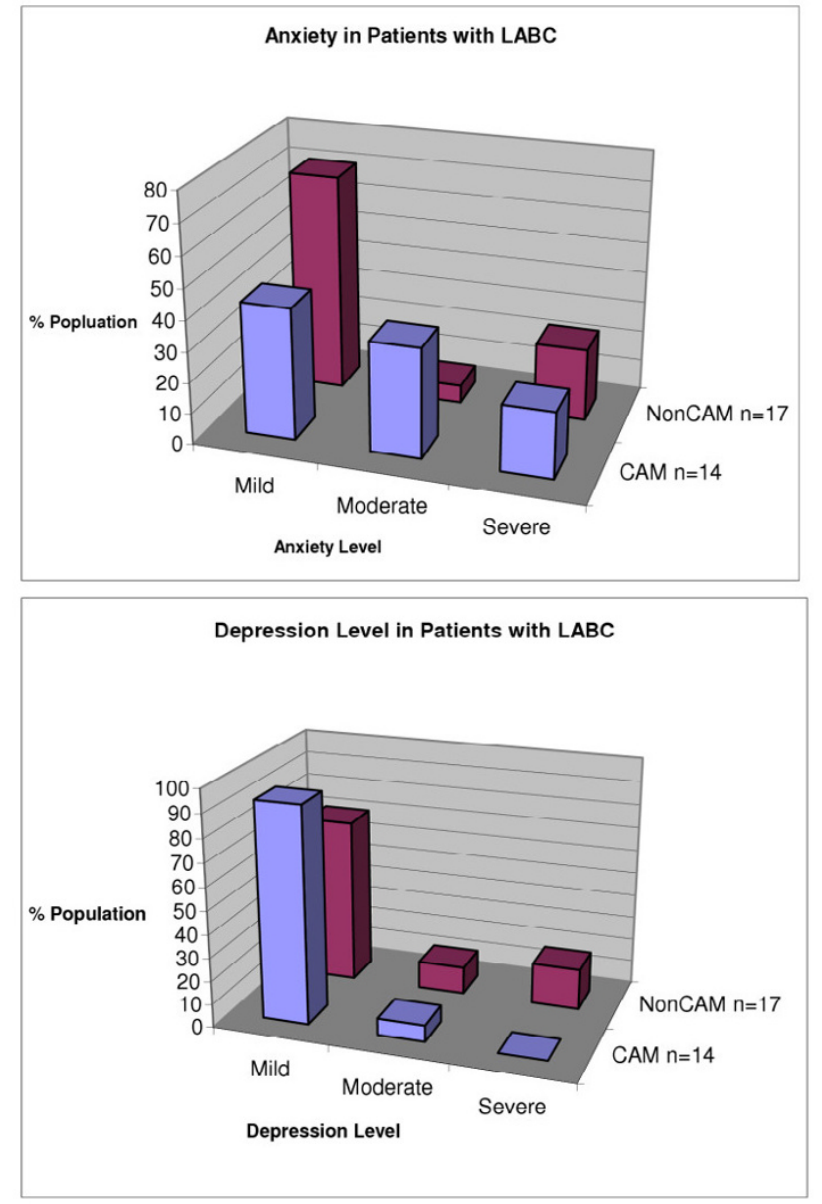

Figure I

Anxiety and Depression Distribution Among Patients with LABC.

modest evidence to show patient benefit with respect to anxiety, depression and quality of life $[23,24]$. The use of CAM therapies has also been shown to correlate with patients coping styles and may fulfil an important psychological need in some patients [25].

The reasons patients give for using CAM are varied, but many concentrate around feelings of control over therapy or of aiding the body over come disease and harmful effects of traditional therapy $[4,26,27]$. Most CAM techniques and substances are felt to be innocuous, as most patients associate 'natural' therapy with safe and nontoxic therapy, a view supported by many health food stores [19]. Side effects and adverse effects are consequently minimized and as a result, poorly communicated to consumers. This perception of 'natural' may encourage patients to take CAM to the exclusion of the conventional therapies with the multiple documented side effects and adverse events [19]. Indeed the global consumption of these therapies continues to rise [9].

Our patient population using CAM was similar to others reported; all woman, in a higher income bracket, currently in a relationship, and more likely to join or be part of a support group $[2,14,25,28,29]$. However, the non-CAM users in our study were more likely to have graduate degrees and thus higher education. This inverse relationship between CAM use and education has been previously described by Dy et al. where participants in phase I trials were found to be less likely to take pharmacologic CAM if they had attained a high level of formal education[30]. However, the majority of evidence supports a higher use of CAM therapy in those with higher socioeconomic and education levels $[2,5,9,25,28,29]$. Ethnicity has also been found to be a CAM stratifying characteristic $[26,29]$. Although we have a small sample size, those of Asian heritage were more likely to pursue CAM therapy. This may emphasize the importance of community and societal support on patient treatment decisions and ultimately cultural acceptance of traditional medicine.

CAM users in our study were more likely to have the support of a partner, family doctor, and be in or interested in joining a support group. This difference in amount of support whether from a partner, family doctor or group delineates our population in a dramatic fashion. The participation in a support group is recognized as highly predictive of CAM use, why is not known but maybe intrinsic to the patients joining the group or as an end result of group interaction $[2,21,29,31]$.

Thirty percent of our patients in the CAM group compared with $14 \%$ in the non-CAM group had combination treatment with surgery, chemotherapy and radiation. Similarly, the literature reflects, the more strenuous the treatment the more likely patients are to use CAM $[5,17]$. Most women used CAM as an adjunct to this intensive therapy, $75 \%$ believe that it helped with symptom control, assisted traditional treatments, boosts the immune system and increased the quality of life, while attributing it little to no curative properties. The majority (86\%) of our patients taking CAM believed that it helped and were positive about their experience. However, two women in our study refused mainstream treatment and were persisting with primary CAM therapy. Due to the questionnaire form we were unable to better characterize this segment of our population.

Earlier studies showed patients using CAM had higher levels of stress, exhibited more severe anxiety and worse depression[3]. These patients consequently had a worse quality of life. As we have previously published, the CAM users in an unselected population of breast cancer patients 
exhibited higher levels of anxiety and depression over the non-users[14]. However, our LABC patients, in actuality seemed to be suffering less severe anxiety and felt their mood to be higher (Figure 1). This maybe explained by Moshen et al., who postulated there are two subgroups of patients, one group who actively copes with stress and another who has considerable adjustment problems [25]. The latter group with adjustment problems were more likely to use greater than four CAM therapies and express a depressive coping behaviour. The five patients who used greater than four CAM therapies in our study described a greater level of anxiety but not depression.

Anxiety is a feeling centred on fear and involves worry, apprehension and dread. Those patients with strong beliefs in CAM therapy are able to lessen these feelings, while those who are 'non-believers' are unable assuage this anxiety. Depression meanwhile, is associated with feelings of sadness and hopelessness; CAM therapy provides a positive influence on conventional treatment and may moderate these thoughts. Differences between CAM users and nonusers with respect to anxiety and depression maybe difficult to show in patients with advanced cancers i.e. LABC, and may explain the difference between the non selected and LABC population.

Our studies primary limitation is sample size, and although our breast centre specializes in treatment of locally advanced breast cancer; with increased screening and education this is becoming a rare diagnosis. Consequently statistical evaluation of the data was unable to be performed and instead a descriptive study was chosen. Small sample size may also account for the discrepancy seen in non-CAM users having a higher level of education. Patient selection in an oncology clinic may have overlooked patients avoiding conventional medicine for treatment of their breast cancer and selection bias may be present. In conclusion, due to the fact this is a single institution study, where the diagnosis and treatment of LABC is a priority the results may not be comparable to other non-selected populations of breast cancer patients.

\section{Conclusion}

Studies are needed to determine the mechanism of action of many of the popular additives, and thus elucidate the side effects and adverse effects. Certainly, CAM therapies are used in part as coping mechanisms by many patients. However the benefits or drawback of this type of therapy is poorly understood, consequently more education and research aimed at both physician and patient is necessary to elucidate the complex psychotherapeutic effect of many of these techniques.

\section{Abbreviations}

CAM complementary alternative medicine
LABC locally advanced breast cancer

\section{Competing interests}

The author(s) declare that they have no competing interests.

\section{Authors' contributions}

LKH - final analysis and drafted the manuscript

BC collected data

SC collected data and did initial analysis

MC conceived the study, participated in its design and coordination and helped draft the manuscript

$\mathrm{BF}, \mathrm{SV}, \mathrm{GD}$ reviewed the manuscript.

All authors read and approved the final manuscript

\section{Additional material}

\section{Additional file 1}

Questionnaire given to women with LABC about their CAM use. Click here for file

[http://www.biomedcentral.com/content/supplementary/14712407-6-39-S1.doc]

\section{Acknowledgements}

The authors would like to thank Lauren Silver for assistance in collecting the data.

\section{References}

I. Eisenberg DM, Kessler RC, Forster C, Norlock FE, Calkins DR, Deldano TL: Unconventional medicine in the United States; prevalence, costs and patterns of use. N Engl J Med 1993, 328:246-252.

2. Boon H, Stewart M, Kennard MA, Sawka C, Brown JB, McWilliam C, Gavin A, Baron RA, Aaron D, Haines-Kamka T: The use of complementary/alternative medicine by breast cancer survivors in Ontario: Prevalence and perceptions. J Clin Oncol 2000, I 8:25I5-252I.

3. Burstein HJ, Gelber S, Guadagnoli E, Weeks J: Use of alternative medicine by women with early-stage breast cancer. $N$ Engl J Med 1999, 340:1733-1739.

4. Ashikage T, Bosompra K, O'Brien P, Nelson L: Use of complementary and alternative medicine by breast cancer patients: prevalence, patterns and communication with physicians. Supp Care Can 2002, 10:542-548.

5. Richardson MA, Sanders T, Palmer JL, Greisinger A, Singletary SE: Complementary/alternative medicine use in a comprehensive cancer centre and the implications of oncology. J Clin Oncol 2000, 18:2505-25I4.

6. Ernst $E$, Casselith BR: The prevalence of complementary/alternative medicine in cancer: a systematic review. Cancer 1998, 83(4):777-782.

7. Astin JA: Why patients use alternative medicine: Results of a national study. JAMA 1998, 279:1548-I553.

8. Crocetti E, Crotti N, Feltrin A, Ponton P, Geddes M, Buiatti : The use of complementary therapies by breast cancer patients attending conventional treatment. Eur / Can 1998, 33:324-328. 
9. Rees RW, Feigel I, Vickers A, Zollman C, McGurk R, Smith C: Prevalence of complementary therapy use by women with breast cancer: a population - based study. E J Cancer 2000, 36:1359-1364.

10. Jacobson JS, Workman S, Kronenberg F: Research on complementary/alternative medicine for patients with breast can cer: a review of the biomedical literature. J Clin Oncol 2000, 18:668-683.

II. Shen J, Andersen R, Albert PS, Wenger N, Glaspy J, Cole M, Shekelle $P$ : Use of complementary/alternative therapies by women with advanced stage breast cancer. BMC Complementary and Alternative Medicine 2002, 2:8.

12. Singletary SE, Allred C, Ashley P, Bassett W, Berry D, Bland KI, Borgen PI, Clark G, Edge SB, Hayes DF, Hutter RVP, Morrow M, Page DL, Recht A, Theriault RL, Thor A, Weaver DL, Wieand S, Green FL: Revision of the American Joint Committee on Cancer staging system for breast cancer. J Clin Oncol 2002, 20:3628-3636.

13. Therasse P, Mauriac L, Welnicka-Jaskiewicz M, Bruning P, Cufer T, Bonnefoi H, Tomiak E, Pritchard KI, Hamilton A, Piccart MJ, EORTC: Final results of a randomized phase III trial comparing cyclophosphamide, epirubicin, and fluorouracil with a dose-intensified epirubicin and cyclophosphamide + filgrastim as neoadjuvant treatment in locally advanced breast cancer: an EORTC-NCIC-SAKK multicenter study. J Clin Oncol 2003, 2I(5):843-50.

14. Rakovitch E, Pignol J, Chartier C, Ezer M, Verma S, Dranitsaris G, Clemons $M$ : Complementary and alternative medicine use is associated with an increased perception of breast cancer risk and death. Breast Cancer Research and Treatment 2005, 90:139-148.

15. Zigmond AS, Snaith RP: The hospital anxiety and depression scale. Acta Psychiatrica Scandinavica 1983, 67(6):361-70.

16. Hopwood P, Howell A, Maguire P: Screening for psychiatric morbidity in patients with advanced breast cancer: validation of two self-report questionnaires. Br / Cancer 1991, 64(2):353-6.

17. Richards MA, Smith P, Ramirez AJ, Fentiman IS, Rubens RD: The influence on survival of delay in the presentation and treatment of symptomatic breast cancer. B J C 1999, 79(5/ 6):858-864.

18. Malik IA, Gopalan S: Use of CAM results in delay in seeking medical advice for breast cancer. Eur J Epidemiol 2003, 18:817-822.

19. Mills E, Ernst E, Singh R, Ross C, Wilson K: Health food store recommendations: implications for breast cancer patients. Breast Cancer Res 2003, 5:170-174.

20. Hisham AN, Yip $\mathrm{CH}$ : Overview of breast cancer in Malaysian women: A problem with late diagnosis. Asian J Surg 2004, 27:130-133.

21. Mohamed I, Williams K, Tamburrino M, Wryobeck J, Carter S: Understanding locally advanced breast cancer: what influences a woman's decision to delay treatment? Prev Med 2005 41:399-405.

22. Ramirez A, Westcombe A, Burgess C, Sutton S, Littlejohns P, Richards $\mathrm{M}$ : Factors predicting delayed presentation of symptomatic breast cancer: a systematic review. Lancet 1999 9159:||27-||3|.

23. Deng G, Cassileth B: Integrative oncology: complementary therapies for pain, anxiety and mood disturbance. CA Cancer J Clin 2005, 55:109-116.

24. Anon: Integration of behavioural and relaxation approaches into the treatment of chronic pain and insomnia. NIH technology assessment panel on integration on behavioral and relaxation approaches into the treatment of chronic pain and insomnia. JAMA 1996, 276:313-318.

25. Moschen R, Kemmler G, Schweigkofler H, Holzner B, Dunser M, Richter R, Fleischhacker WW, Sperner-Unterweger B: Use of alternative/complementary therapy in breast cancer patients a psychological perspective. Support Care Cancer 200I, 9:267-274.

26. Cui Y, Shu X, Gao Y, Wen W, Ruan Z, Jin F, Zheng W: Use of complementary and alternative medicine by Chinese women with breast cancer. Breast Cancer Research and Treatments 2004 , 85:263-270.

27. Patterson R, Neuhouser ML, Hedderson MM, Schwartz SM, Standish LJ, Bowen DJ, Marshall LM: Types of alternative medicine used by patients with breast cancer, or prostate cancer: predictors, motives and costs. J Altern and Complement Med 2004, 8:477-485.
28. Navo MA, Phan J, Vaughan C, Palmer JL, Michaud L, Jones KL, Bodurka DC, Basen-engquist K, Hortobagyi GN, Kavanagh JJ, Smith JA: An assessment of the utilization of complementary and alternative medication in women with gynecologic or breast malignancies. J Clin Oncol 2004, 22:67I-677.

29. Lee M, Lin S, Wrensch M, Adler S, Eisenberg D: Alternative therapies used by women with breast cancer in four ethnic populations. J Natl Cancer Inst 2000, 92(I):42-47.

30. Dy GK, Bekele L, Hanson LJ, Furth A, Mandrekar S, Sloan JA, Adjei AA: Complementary and alternative medicine use by patients enrolled onto phase I clinical trials. J Clin Oncol 2004, 23:4810-48I5.

31. Nagel G, Hoyer H, Katenkamp D: Use of complementary and alternative medicine by patients with breast Cancer: observations from a health survey. Supp Care Cancer 2004, I2(II):789-796.

\section{Pre-publication history}

The pre-publication history for this paper can be accessed here:

http://www.biomedcentral.com/1471-2407/6/39/prepub
Publish with Biomed Central and every scientist can read your work free of charge

"BioMed Central will be the most significant development for disseminating the results of biomedical research in our lifetime. "

Sir Paul Nurse, Cancer Research UK

Your research papers will be:

- available free of charge to the entire biomedical community

- peer reviewed and published immediately upon acceptance

- cited in PubMed and archived on PubMed Central

- yours - you keep the copyright
BioMedcentral 